\title{
Electrodeposition of Hydroxyapatite-Multiwalled Carbon Nanotube Nanocomposite on Ti6Al4V
}

\author{
Thom T. Nguyen $\mathbb{D},{ }^{1,2}$ Nam T. Pham, ${ }^{1}$ Thanh T. M. Dinh $\mathbb{D},{ }^{2,3}$ Thu T. Vu, ${ }^{3}$ Hai S. Nguyen, ${ }^{4}$ \\ and Lam D. Tran ${ }^{1}$ \\ ${ }^{1}$ Institute for Tropical Technology, Vietnam Academy of Science and Technology, Hanoi 122100, Vietnam \\ ${ }^{2}$ Graduate University of Science and Technology, Vietnam Academy of Science and Technology, Hanoi 122100, Vietnam \\ ${ }^{3}$ University of Science and Technology of Hanoi, Vietnam Academy of Science and Technology, Hanoi 122100, Vietnam \\ ${ }^{4}$ Military Institute of Traditional Medicine, Hanoi 128200, Vietnam
}

Correspondence should be addressed to Thom T. Nguyen; ntthom@itt.vast.vn

Received 3 July 2019; Revised 14 February 2020; Accepted 27 February 2020; Published 15 April 2020

Academic Editor: Sagar Roy

Copyright (c) 2020 Thom T. Nguyen et al. This is an open access article distributed under the Creative Commons Attribution License, which permits unrestricted use, distribution, and reproduction in any medium, provided the original work is properly cited.

\begin{abstract}
This work aims to study the optimal conditions to synthesize hydroxyapatite-multiwalled carbon nanotube (HAp-MWCNT) coatings on Ti6Al4V by electrodeposition technique. The structural behaviors, morphology, and mechanical properties of the coatings were characterized by various advanced methods. The analyzed results showed that the obtained coatings were composed of hydroxyapatite (HAp) and multiwalled carbon nanotube (MWCNT) phases. The presence of MWCNTs in the HAp-MWCNT composite, which improved adhesion between the coatings and the substrate about 2.3 times, increased $20 \%$ of hardness and decreased about $40 \%$ the solubility of HAp-MWCNTs/Ti6Al4V in comparison with pure HAp coating on Ti6Al4V.
\end{abstract}

\section{Introduction}

Multiwalled carbon nanotubes have recently attracted many attention in biomedical applications due to their extraordinary behaviors, including large surface area, high tensile strength, good corrosion resistance, and good biocompatibility [1-4]. Many research groups have reported the use of this fantastic material in manufacturing highly conductive electrodes for sensor and neural stimulation [2, 3]. For bone implant, the presence of such a durable material in the mineral composite can significantly increase the strength of the tissue/bone joint and somehow stimulate new bone formation [5-8].

The HAp-MWCNT nanocomposite coatings can be fabricated by many techniques, including coprecipitation, pulsed electrodeposition, shear mixing, sprayed plasma, electrophoretic deposition and electrodeposition [6, 8-14]. By coprecipitation, a large amount of HAp-MWCNTs can be obtained. However, the obtained materials are not pure with the presence of different compounds of calcium phosphate.
Studies show that using sprayed plasma to form HApMWCNTs has good adhesion with the substrate, but the high temperature causes the formation of tricalcium phosphate $\left(\left(\mathrm{Ca}_{3}\left(\mathrm{PO}_{4}\right)_{2}\right), \mathrm{TCP}\right)$ [8]. Electrodeposition seems to be the most attractive and promising technique to fabricate HApMWCNT coatings on the surface of metals or alloys. This method has many advantages such as low process temperature, ability to coat geometrically complex surfaces, convenience to control the coating properties, and low cost [15].

Nowadays, 316L SS and Ti6Al4V are commonly used as biomedical bone screws [16]. In our previous studies, HApMWCNT coating was successfully deposited on the surface of 316L SS [17-19]. Over time, studies to find more advanced materials are necessary. So, the aim of this work is to develop a new nanocomposite coating based on hydroxyapatite and carbon nanotubes on the surface of the Ti6Al4V biometallic alloy. The effects of synthesis condition such as scanning potential range, scanning rate, number of scans, synthesis temperature, and MWCNT content on the characterization 
of the obtained coatings were investigated. The results allow us to select the most suitable conditions to synthesize HApMWCNT/Ti6Al4V material.

\section{Materials and Methods}

2.1. Materials. Calcium nitrate hydrate $\left(\mathrm{Ca}\left(\mathrm{NO}_{3}\right)_{2} \cdot 4 \mathrm{H}_{2} \mathrm{O}\right.$, $99 \%$ pure), ammonium dihydrogen phosphate $\left(\mathrm{NH}_{4} \mathrm{H}_{2} \mathrm{PO}_{4}\right.$, $99 \%$ pure), sodium nitrate $\left(\mathrm{NaNO}_{3}, 99 \%\right.$ pure $)$, nitric acid $\left(\mathrm{HNO}_{3}, 67\right.$ wt.\%), and sulfuric acid $\left(\mathrm{H}_{2} \mathrm{SO}_{4}, 98\right.$ wt.\%) were purchased from Sigma-Aldrich. Multiwalled carbon nanotubes (MWCNTs) (diameter of $15-90 \mathrm{~nm}$ and length of $1-10 \mu \mathrm{m}, 93 \%)$ were given by the Institute of Materials Science, Vietnam Academy of Science and Technology (Hanoi, Vietnam) [20]. The substrates Ti6Al4V (composed of $89.63 \% \mathrm{Ti}, 6.04 \% \mathrm{Al}, 4.11 \% \mathrm{~V}, 0.05 \% \mathrm{C}$, and $0.17 \% \mathrm{Fe}$ ) were purchased from Gloria Material Technology Corp (Taipei, Taiwan).

\subsection{Preparation of Carboxylated Multiwalled Carbo-} nanotubes (MWCNTs-COOH). Multiwalled carbon nanotubes were functionalized with carboxylic functional groups by treatment in a mixture of acids $\left(\mathrm{HNO}_{3}: \mathrm{H}_{2} \mathrm{SO}_{4}=1: 3\right)$ at $110^{\circ} \mathrm{C}$ for $1 \mathrm{~h}$ under continuous magnetic stirring [13]. The carboxylated product was filtered and washed with distilled water several times until no residual acid was found. The final product was dried and stored in ambient conditions until use. MWCNTs before and after modification process were characterized in our previous publications [18]. It confirms the formation of -COOH groups after modification process.

2.3. Electrodeposition of HAp-MWCNTs on Ti6Al4V [18, 19]. The electrolyte solution $(\mathrm{pH}=4.4)$ containing $30 \mathrm{mM}$ $\mathrm{Ca}\left(\mathrm{NO}_{3}\right)_{2}, 18 \mathrm{mM} \mathrm{NH}_{4} \mathrm{H}_{2} \mathrm{PO}_{4}$, and $150 \mathrm{mM} \mathrm{NaNO}_{3}$ was first prepared in distilled water. After that $\mathrm{MWCNTs}-\mathrm{COOH}$ material was dispersed in the electrolyte solution using an intense ultrasonication treatment for ten minutes at different concentrations $\left(0-1 \mathrm{~g} \cdot \mathrm{L}^{-1}\right)$. These solutions are denoted as HAp, HAp-MWCNTs ${ }_{0.25}$, HAp-MWCNTs H. $_{0.5}$, HApMWCNTs $_{0.75}$, and HAp-MWCNTs ${ }_{1.0}$ corresponding to the MWCNTs-COOH concentration of $0,0.25,0.5,0.75$, and $1.0 \mathrm{~g} \cdot \mathrm{L}^{-1}$, respectively.

Electrodeposition of HAp with and without MWCNTs$\mathrm{COOH}$ was carried out on the biologic electrochemical workstation (VSP-300, France) using a cell of three-electrode setup. A platinum grid was used as the counter electrode, while a $\mathrm{Hg} / \mathrm{Hg}_{2} \mathrm{Cl}_{2} / \mathrm{KCl}$ (SCE) electrode was used as the reference electrode. A Ti6Al4V sheet $\left(1.5 \times 1 \times 0.2 \mathrm{~cm}^{3}\right)$ was used as the working electrode. The working area was limited to be $1 \mathrm{~cm}^{2}$ using epoxy glue. The working electrode was polished, then washed with distilled water, and finally dried under nitrogen gun right before use. The electrodeposition process of HAp, HAp-MWCNTs ${ }_{0.25}$, ${\mathrm{HAp}-\mathrm{MWCNTs}_{0.5} \text {, HAp-MWCNTs }}_{0.75}$, and HApMWCNTs $_{1.0}$ onto the Ti6Al4V electrode was performed using cyclic voltammetry technique. Different synthesis conditions (scanning potential ranges, number of scans, and temperature) were investigated. All the obtained samples were rinsed thoroughly with distilled water before being dried at $80^{\circ} \mathrm{C}$ in vacuum for $24 \mathrm{~h}$.

2.4. Morphology and Structural Behaviors of HAp and HApMWCNT Coatings. The morphology of the coatings was examined by using JEOL-JSM-6510LV field emission scanning electron microscopy (SEM) operated at $20 \mathrm{kV}$. More details on morphological behaviors of the coatings at a smaller scale were also tested with using atomic force microscopy (AFM) (XE-100 Park Systems).

Fourier transform infrared (FTIR), Raman spectroscopy (excitation wavelength of $633 \mathrm{~nm}$ ) (IS10, NEXUS), and $\mathrm{X}$-ray diffraction $\left(\mathrm{Cu}-\mathrm{K}_{\alpha}\right.$ radiation, $\left.40 \mathrm{kV}\right)$ (SIEMENS D5005 Bruker-Germany) techniques were used to test structural behaviors of the materials.

The mass of the electrodeposited coatings was determined from the subtraction between the mass of the Ti6Al4V electrode before and after modification (balanced by the Precisa analytical balance, XR 205 SM-PR, Swiss). The thickness of HAp-MWCNT coating is measured by the Alpha-Step IQ system (KLA-Tencor, USA), which is a surface morphology device that operates on the needle contact principle, according to the ISO 4288-1998 standard at the Institute of Materials Science, Vietnam. The obtained result is the average value of 5 measurements.

\subsection{Mechanic Properties of HAp and HAp-MWCNT} Coatings. The adhesion of HAp and HAp-MWCNT coatings onto Ti6Al4V substrates was evaluated by tensile testing following the ASTM F1044 standard [21]. The hardness and elastic modulus of the coatings were determined using Mikrohärte-Prüfeinrichtung $\mathrm{mhp} 100$ following TCVN-258-1:2007 Vietnam standard and MTS $793(\mathrm{~g})$, USA. The dissolution of HAp or HAp-MWCNT coatings in $20 \mathrm{~mL}$ of $0.9 \% \mathrm{NaCl}$ solution at different soaked times was determined through $\mathrm{Ca}^{2+}$ concentration using atomic absorption apectrometry (iCE-3500, Thermo, Germany).

\section{Results and Discussion}

\subsection{Effect of Process Parameters on the Properties of the Obtained Coatings}

3.1.1. Electrodeposition of HAp-MWCNT Coatings. The growth mechanism of HAp-based materials on the electrode surface can be expressed in equations (1)-(7). At first, hydroxyl ions $\left(\mathrm{OH}^{-}\right)$and phosphate anions $\left(\mathrm{PO}_{4}{ }^{3-}\right)$ are generated from water reduction (equation (1)) and hydrogen phosphate anions $\left(\mathrm{H}_{2} \mathrm{PO}_{4}{ }^{-}\right.$and $\left.\mathrm{HPO}_{4}{ }^{2-}\right)$ (equations (2) and (3), respectively). Later, these ions react with calcium cations $\left(\mathrm{Ca}^{2+}\right)$ to provide a white precipitate (HAp) which is deposited directly onto the electrode surface (equation (5)). In the same time, MWCNTs-COOH material which might be bonded to HAp through hydrogen bonds between carboxylic and hydroxyl groups [22] will also be trapped into HAp coatings. The presence of carbonaceous material in HAp coatings might be observed visibly by a slight color 
change from white to grey white. It is worthy to note that the occurrence of hydrogen bubbles during electrodeposition process is unavoidable. This continuous formation of hydrogen gas at the electrode-electrolyte interface will surely increase the roughness and somehow reduce the adhesion of HAp-based coatings. In addition, some undesired add products such as octacalcium phosphate (OCP) and dicalcium phosphate dehydrate (DCPD) might be also be present in HAp-based coatings. Probably, it is essential to control precisely the major factors that affect directly the growth process such as sweeping potential range, content of carbonaceous nanomaterial, and temperature.

Reactions occurred during electrodeposition of HAp onto the electrode surface. Note the potentials at which these reactions occur in this scheme:

$$
\begin{aligned}
\mathrm{O}_{2}+2 \mathrm{H}_{2} \mathrm{O}+4 e^{-} & \longrightarrow 4 \mathrm{OH}^{-} \\
\mathrm{H}_{2} \mathrm{PO}_{4}^{-}+e^{-} & \longrightarrow \mathrm{HPO}_{4}^{2-}+\frac{1}{2} \mathrm{H}_{2} \uparrow \\
\mathrm{HPO}_{4}^{2-}+e^{-} & \longrightarrow \mathrm{PO}_{4}^{3-}+\frac{1}{2} \mathrm{H}_{2} \uparrow \\
2 \mathrm{H}_{2} \mathrm{O}+2 e^{-} & \longrightarrow \mathrm{H}_{2} \uparrow+2 \mathrm{OH}^{-} \\
10 \mathrm{Ca}^{2+}+6 \mathrm{PO}_{4}^{3-}+2 \mathrm{OH}^{-} & \longrightarrow \mathrm{Ca} 10\left(\mathrm{PO}_{4}\right)_{6}(\mathrm{OH})_{2}
\end{aligned}
$$$$
\text { (hydroxyapatite, HAp) } 49
$$

$$
4 \mathrm{Ca}^{2+}+\mathrm{HPO}_{4}^{2-}+2 \mathrm{PO}_{4}^{3-}+2.5 \mathrm{H}_{2} \mathrm{O} \longrightarrow \mathrm{Ca}_{4} \mathrm{H}\left(\mathrm{PO}_{4}\right)_{3} \cdot 2.5 \mathrm{H}_{2} \mathrm{O}
$$

(octacalcium phosphate, OCP)

$$
\begin{aligned}
& \mathrm{Ca}^{2+}+\mathrm{HPO}_{4}^{2-}+2 \mathrm{H}_{2} \mathrm{O} \longrightarrow \mathrm{CaHPO}_{4} \cdot 2 \mathrm{H}_{2} \mathrm{O} \\
& \quad \text { (dicalcium phosphate dihydrate, } \mathrm{DCPD} \text { ) }
\end{aligned}
$$

3.1.2. Effect of Potential Range. Figure 1 presents the electrodeposition of HAp-MWCNTs 0.5 coatings onto Ti6Al4V using cyclic voltammetry technique by sweeping from $0 \mathrm{~V}$ to $-2.1 \mathrm{~V}$ (vs. SCE) at a scan rate of $5 \mathrm{mV} \cdot \mathrm{s}^{-1}$, number of scans of 5 , and temperature of $45^{\circ} \mathrm{C}$. It can be seen from Figure 1 that the current density is kept nearly constant at less negative potentials $(0 \mathrm{~V}$ to $-1.2 \mathrm{~V})$ and then starts to change at around $-1.2 \mathrm{~V}$ and finally increases rapidly $[23,24]$. This is an important evidence on the formation of localized $\mathrm{OH}^{-}$ions that will facilitate the growth of HAp-based materials on the electrode surfaces.

In fact, the current density is one of the most important factors that determine the thickness of the electrodeposited layer [25]. Herein, we have investigated the growth kinetics of HAp-MWCNTs ${ }_{0.5}$ coatings by sweeping in 5 scans and stopping at different potentials ranging from $-1.4 \mathrm{~V}$ to $-2.1 \mathrm{~V}$ with an interval of $0.1 \mathrm{~V}$. All preliminary observations on thickness, mass, and adhesion of the HAp$\mathrm{MWCNTs}_{0.5}$ coatings with different potential ranges are

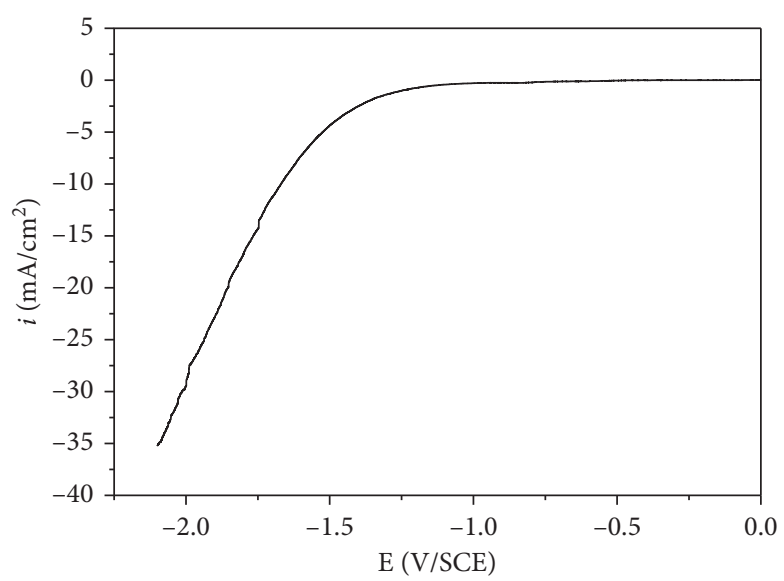

Figure 1: The cathodic polarization curve of Ti6Al4V in the electrolyte solution.

provided in Table 1. At very low current densities of only $-2.4 \mathrm{~mA} \cdot \mathrm{cm}^{-2}$ (stopped potential of $-1.4 \mathrm{~V}$ ) and $-4.5 \mathrm{~mA} \cdot \mathrm{cm}^{-2}$ (stopped potential of $-1.5 \mathrm{~V}$ ), the growth of HAp-MWCNTs ${ }_{0.5}$ was strictly limited. Obviously, thicker coatings were obtained with increasing current density. A very thick coating with thickness of $7 \mu \mathrm{m}$ and mass density of $2.33 \mathrm{mg} \cdot \mathrm{cm}^{-2}$ was obtained at the highest current density of $-35 \mathrm{~mA} \cdot \mathrm{cm}^{-2}$ (stopped potential of $-2.1 \mathrm{~V}$ ). In general, these HAp-MWCNTs 0.5 coatings might be qualified for further biomedical applications in terms of the thickness (several micrometers). Unfortunately, the adhesion of HAp-MWCNTs ${ }_{0.5}$ coatings onto the substrate was found to be declined with their thickness. This value was slightly decreased from $12.2 \mathrm{MPa}$ to $10.4 \mathrm{MPa}$ as increasing the coating thickness from 4.0 to $6.3 \mu \mathrm{m}$ and then suddenly dropped to $7.6 \mathrm{MPa}$ at the thickness of $7 \mu \mathrm{m}$. The evolution of hydrogen bubbles during water electrolysis at negative potentials is responsible for the low adhesion of the coatings $[26,27]$. The HAp-MWCNTs ${ }_{0.5}$ coating obtained at a sweeping range from $0 \mathrm{~V}$ to $-2.0 \mathrm{~V}$ with considerable thickness $(6.3 \mu \mathrm{m})$ and acceptable adhesion $(10.4 \mathrm{MPa})$ seems to be the most suitable for further applications. Therefore, the stopped potential for cyclic electrodeposition will be chosen to be $-2.0 \mathrm{~V}$ for all further experiments.

The structural behaviors of HAp-MWCNTs $\mathrm{M}_{0.5}$ coatings deposited at different potential ranges were examined by FTIR and XRD techniques. Figure 2(a) presents the FT-IRR spectrum of MWCNTs-COOH with the characteristic peak of the -COOH group observed at $1735 \mathrm{~cm}^{-1}$ and $1380 \mathrm{~cm}^{-1}$ which was characterized for $\mathrm{C}=\mathrm{O}$ and $\mathrm{C}-\mathrm{OH}$ bindings. Bands in the range $1630 \mathrm{~cm}^{-1}$ are characteristic for carbonaceous materials and are most often associated with the occurrence of the $\mathrm{C}-\mathrm{C}$ stretching bonds characteristic to the expected nanotube phonon modes. FTIR spectrum of HAp-MWCNTs shows characteristic vibration modes of HAp $\left(1030,610\right.$, and $\left.560 \mathrm{~cm}^{-1},-\mathrm{PO}_{4}\right)$ and MWCNTs-COOH (3430-3440 $\mathrm{cm}^{-1}$, stretching, -OH; and $1630 \mathrm{~cm}^{-1}$, C-C stretching) (Figure 2(c)). The spectral shoulder of $\mathrm{C}=\mathrm{O}$ at the wavenumber of $1735 \mathrm{~cm}^{-1}$ was not observed due 
TABLE 1: Mass, thickness, and adhesion of HAp-MWCNTs synthesized at different potential ranges.

\begin{tabular}{lccr}
\hline Potential range $(\mathrm{V} / \mathrm{SCE})$ & Mass $\left(\mathrm{mg} / \mathrm{cm}^{2}\right)$ & Thickness $(\mu \mathrm{m})$ ISO $4288-1998$ & Adhesion $(\mathrm{MPa})$ \\
\hline $0 \div-1.4$ & - & - & - \\
$0 \div-1.5$ & - & - & - \\
$0 \div-1.6$ & $1.32 \pm 0.04$ & $4.0 \pm 0.74$ & $12.2 \pm 0.52$ \\
$0 \div-1.7$ & $1.43 \pm 0.03$ & $4.3 \pm 0.62$ & $11.9 \pm 0.80$ \\
$0 \div-1.8$ & $1.64 \pm 0.02$ & $4.9 \pm 0.85$ & $11.6 \pm 0.42$ \\
$0 \div-1.9$ & $1.88 \pm 0.02$ & $5.7 \pm 0.94$ & $11.0 \pm 0.35$ \\
$\mathbf{0}-\mathbf{2 . 0}$ & $\mathbf{2 . 0 8} \pm 0.03$ & $\mathbf{6 . 3} \pm 1.00$ & $\mathbf{1 0 . 4}$ \\
$0 \div-2.1$ & $2.33 \pm 0.05$ & $7.0 \pm 1.04$ & $7.4 \pm 0.72$ \\
\hline
\end{tabular}

to its small intensity. In addition, the position of the stretching vibration mode $-\mathrm{OH}$ in the carboxylic group of MWCNTs $\left(1380 \mathrm{~cm}^{-1}\right)$ was found to be red-shifted by $20 \mathrm{~cm}^{-1}$ (at $1360 \mathrm{~cm}^{-1}$ ), indicating the formation of hydrogen bonds between calcium ions in the HAp and carboxylic groups of MWCNTs [13, 28, 29]. It means that HAp and MWCNTs have surely been codeposited onto the substrate. XRD patterns (Figure 3) have also confirmed the presence of HAp (JCPDS 09-432) and MWCNT (JCPDS 01-075-1621) materials in all samples. It must be noted that the diffraction peak at $2 \theta=25.8^{\circ}$ of HAp and diffraction peak at $2 \theta=26^{\circ}$ of MWCNTs are superpositioned. Remarkably, some diffraction peaks $\left(2 \theta \sim 29^{\circ}, 43^{\circ}\right.$, and $\left.51^{\circ}\right)$ relevant to dicalcium phosphate dihydrate (DCDP, $\mathrm{CaH}$ $\mathrm{PO}_{4} \cdot 2 \mathrm{H}_{2} \mathrm{O}$ ) were also found at low current densities (stopped potentials $-1.6 \mathrm{~V}$ and $-1.7 \mathrm{~V}$ ). This might be resulted from low concentration of hydroxyl groups at the electrode surface which is not enough to convert completely $\mathrm{HPO}_{4}{ }^{2-}$ ions to $\mathrm{PO}_{4}{ }^{3-}$ during HAp deposition. Again, these results have firmly confirmed that the stopped potential of $-2.0 \mathrm{~V}$ is the best choice for the electrodeposition of HAp-MWCNT coatings.

FE-SEM images of HAp-MWCNTs ${ }_{0.5}$ coatings obtained at different potential ranges are given in Figure 4. As seen from Figure 4, the Ti6Al4V substrate was fully covered by microporous HAp-MWCNTs ${ }_{0.5}$ material. The porosity of the coatings was found to be increased with increasing applied current density. Probably, the occurrence of hydrogen gas at the electrolyte-electrode interface is responsible for such a high porosity accompanying with low adhesion of the coatings.

3.1.3. Effect of the MWCNTs-COOH Content. Figure 5 shows the polarization curves of the Ti6Al4V electrode sweeping in the electrolyte containing different amount of MWCNTs$\mathrm{COOH}\left(0-1 \mathrm{~g} \cdot \mathrm{L}^{-1}\right)$ between 0 and $-2 \mathrm{~V}$ (vs. SCE) at $45^{\circ} \mathrm{C}$ and scan rate of $5 \mathrm{mV} \cdot \mathrm{s}^{-1}$. Clearly, the cathodic current density was increased with increasing MWCNT amount due to the high conductivity of this carbonaceous material. FTIR spectra (Figure 6) and XRD patterns (Figure 7) of HAp-MWCNT coatings with different amounts of MWCNTs $\left(0-1 \mathrm{~g} \cdot \mathrm{L}^{-1}\right)$ have shown structural characteristics of pure HAp and MWCNTs. No add products (neither OCP nor DCPD) were observed.

The mass, thickness, and adhesion of these HApMWCNT coatings are given in Table 2. As seen from Table 2,

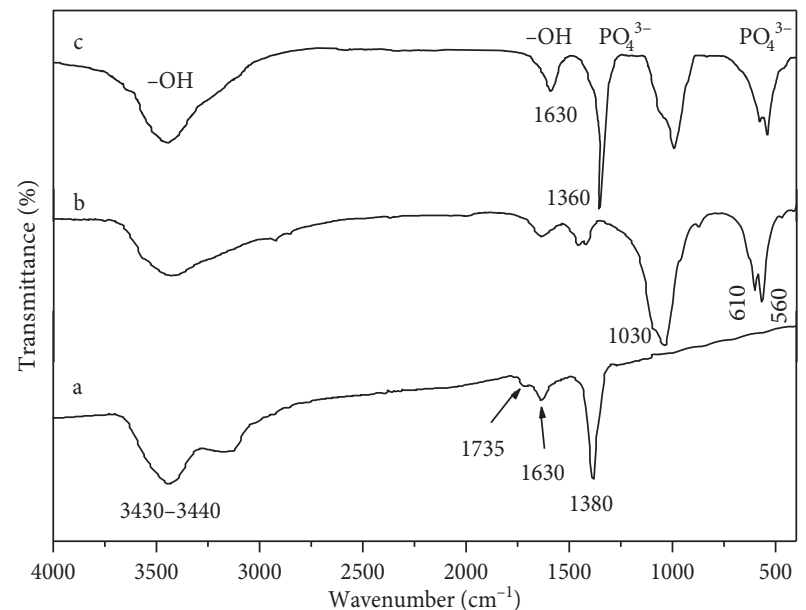

FIgURE 2: FTIR of (a) MWCNTs, (b) HAp, and (c) optimal HApMWCNT coatings.

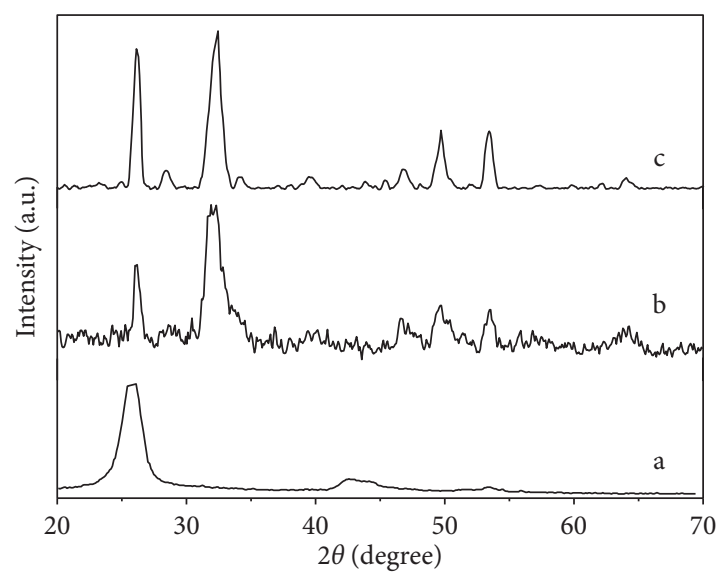

FIGURE 3: XRD patterns of (a) MWCNTs, (b) HAp, and (c) optimal HAp-MWCNT coatings.

the thickness and mass of HAp-based coatings are decreased while adding MWCNTs-COOH into the deposition solution. MWCNT material with long tubes and voluminous molecular structure might have prevented the formation of HAp-MWCNT coatings on the surface of Ti6Al4V. Remarkably, the growth of HAp-MWCNTs is seriously limited at carbonaceous content of more than $0.5 \mathrm{~g} \cdot \mathrm{L}^{-1}$. Nevertheless, the adhesion of HAp-based coatings is found to be 


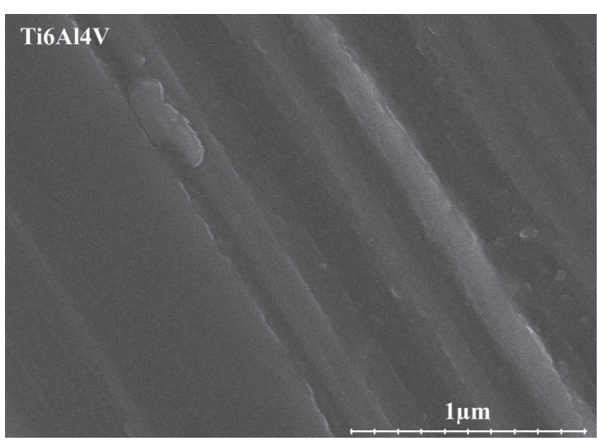

(a)

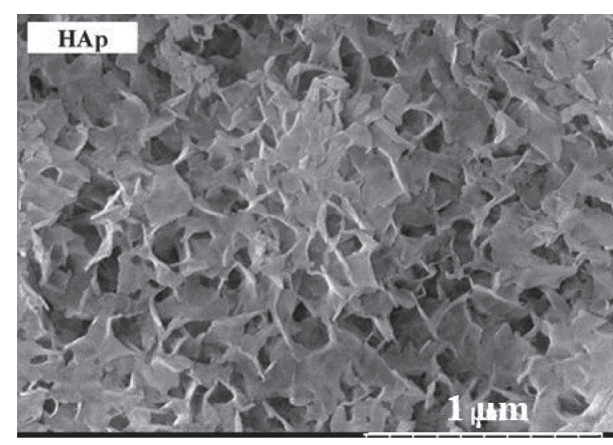

(b)

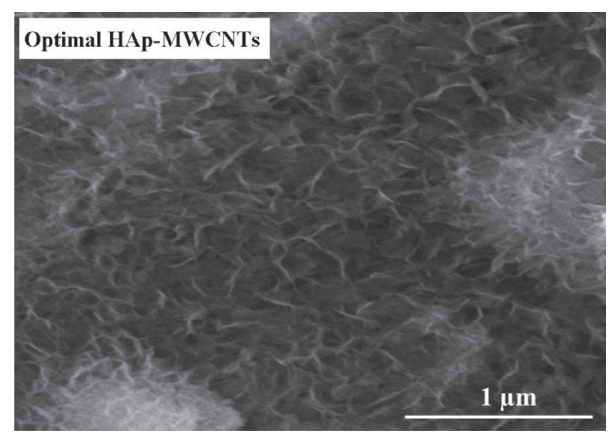

(c)

Figure 4: SEM images of bare (a) Ti6Al4V electrode, (b) HAp, and (c) optimal HAp-MWCNT coatings.

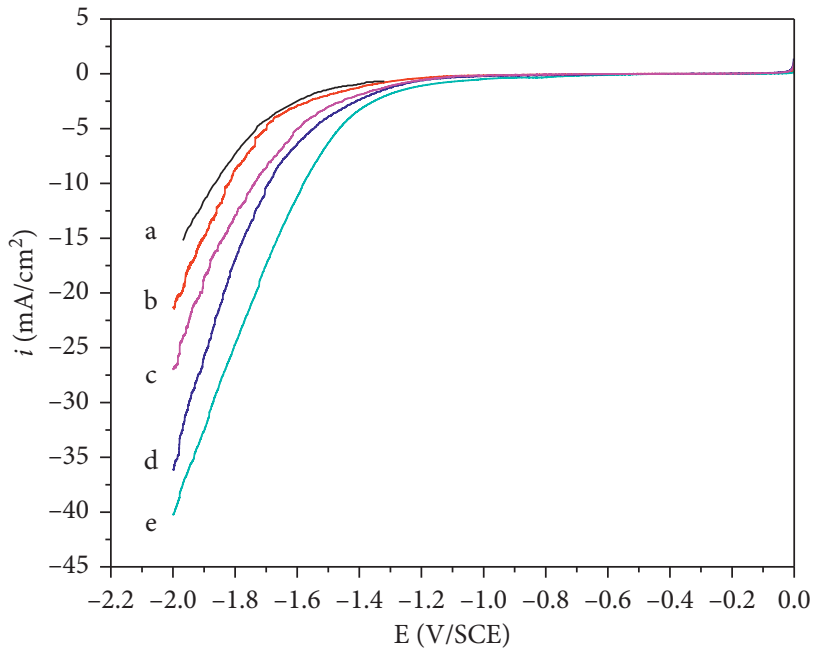

FIGURE 5: Cathodic polarization curves of the Ti6Al4V electrode in the electrolyte containing different amount of MWCNTs-COOH: (a) 0 , (b) 0.25 , (c) 0.5 , (d) 0.75 , and (e) $1 \mathrm{~g} \cdot \mathrm{L}^{-1}$.

improved significantly in presence of MWCNTs and is the strongest $(10.4 \mathrm{MPa})$ at MWCNT concentration of $0.5 \mathrm{~g} \cdot \mathrm{L}^{-1}$. The obtained coatings were tighter in the cases of the presence of MWCNTs because of the formation of hydrogen bonds between - $\mathrm{COOH}$ groups of MWCNTs and $-\mathrm{OH}$ groups of HAp. But, the high amount of MWCNTs in the electrolyte $(0.75 \mathrm{~g} / \mathrm{L}$ or $1.0 \mathrm{~g} / \mathrm{L})$ was the cause of agglomeration of MWCNTs-COOH in the coatings, leading to a strong decrease in adhesion strength. Therefore, $0.5 \mathrm{~g} \cdot \mathrm{L}^{-1}$ MWCNTs-COOH was selected for further studies.

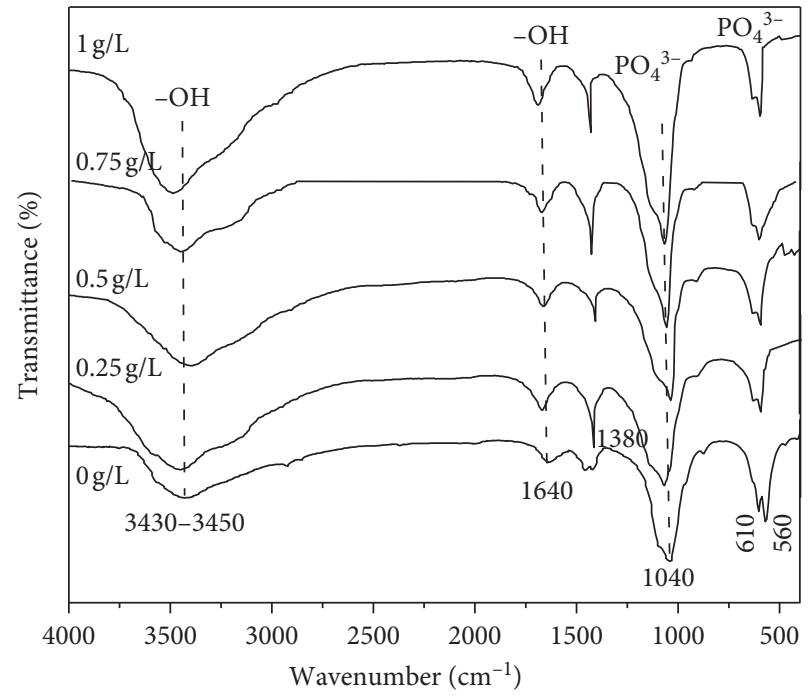

Figure 6: FTIR spectra of HAp-MWCNTs synthesized with different amount of MWCNTs.

3.1.4. Effect of Synthesis Temperature. To investigate the effect of temperature on behaviors of the obtained coatings, the electrodeposited temperature was controlled at $30^{\circ} \mathrm{C}$, $45^{\circ} \mathrm{C}$, and $60^{\circ} \mathrm{C}$. The cathodic polarization curves recorded during electrodeposition of HAp-MWCNTs ${ }_{0.5}$ coatings at different temperatures are depicted in Figure 8. When the synthesis temperature increased from $30^{\circ} \mathrm{C}$ to $60^{\circ} \mathrm{C}$, the cathodic current density increased. Probably, the reactions occurring during the growth of HAp-MWCNT coatings have been accelerated by the heat. Obviously, the mass and 


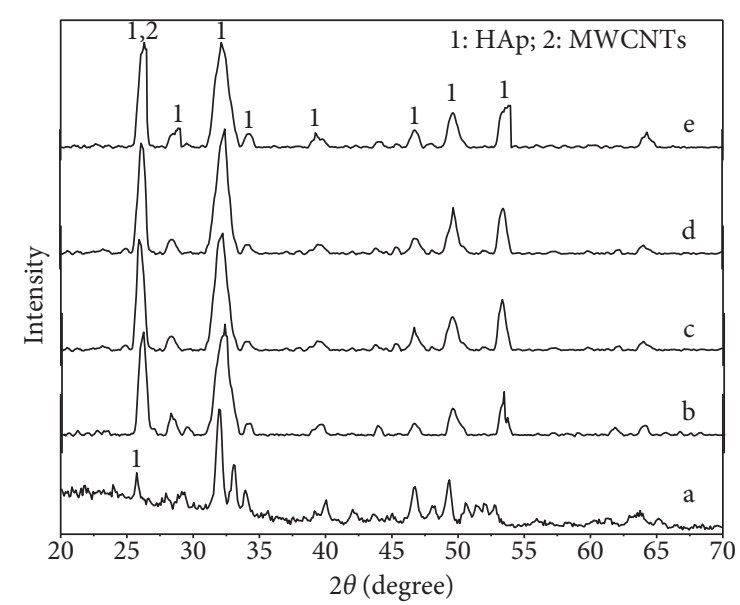

FIGURE 7: XRD patterns of (a) HAp, (b) HAp-MWCNTs ${ }_{0.25}$, (c) HApMWCNTs $_{0.5}$, (d) HAp-MWCNTs 0.75 , and (e) HAp-MWCNTs ${ }_{1}$.

TABLE 2: The variation of mass, thickness, and adhesion of HApMWCNT coatings with the Ti6Al4V substrate.

\begin{tabular}{lccc}
\hline $\begin{array}{l}\text { MWCNT } \\
\text { amount }(\mathrm{g} / \mathrm{L})\end{array}$ & $\begin{array}{c}\text { Mass }(\mathrm{mg} / \\
\left.\mathrm{cm}^{2}\right)\end{array}$ & $\begin{array}{c}\text { Thickness }(\mu \mathrm{m}) \\
\text { ISO 4288-1998 }\end{array}$ & $\begin{array}{c}\text { Adhesion } \\
(\mathrm{MPa})\end{array}$ \\
\hline 0 & $2.81 \pm 0.02$ & $8.9 \pm 0.82$ & $4.5 \pm 0.8$ \\
0.25 & $2.19 \pm 0.04$ & $6.8 \pm 0.61$ & $9.2 \pm 0.52$ \\
$\mathbf{0 . 5}$ & $\mathbf{2 . 0 8} \pm 0.02$ & $\mathbf{6 . 3} \pm 0.84$ & $\mathbf{1 0 . 4} \pm 0.45$ \\
0.75 & $1.56 \pm 0.05$ & $4.7 \pm 1.05$ & $7.1 \pm 0.64$ \\
1 & $1.34 \pm 0.08$ & $4.1 \pm 1.04$ & $6.2 \pm 0.82$ \\
\hline
\end{tabular}

the thickness of HAp-MWCNTs $\mathrm{s}_{0.5}$ coatings were found to be increasing rapidly with increasing synthesis temperature (Table 3). However, the adhesion of these coatings was decreased strongly and reached $6 \mathrm{MPa}$ at $60^{\circ} \mathrm{C}$. The results showed clearly that at high temperature, the reaction rate to form $\mathrm{H}_{2}$ gas on the surface of the Ti6Al4V electrode increased leading to obtained porous coatings. Therefore, the electrodeposited temperature of $45^{\circ} \mathrm{C}$ was selected to synthesize HAp-MWCNTs/Ti6Al4V. XRD patterns (Figure 9) have shown only characteristic peaks of HAp and MWCNT materials. The morphology of HAp-MWCNTs films grown in the Ti6Al4V substrate (Figure 10) exhibits coral-like shape at lower temperatures $\left(30\right.$ and $\left.45^{\circ} \mathrm{C}\right)$ but turn into leaf-like shape with large size at higher temperature $\left(60^{\circ} \mathrm{C}\right)$. It is supposed that the high growth speed of the apatite crystal is the main reason for this morphology transition [30].

3.1.5. Effect of Number of Scans. In this section, HAp$\mathrm{MWCNTs}_{0.5}$ coatings were synthesized at a potential range of $0 \div-2.0 \mathrm{~V}$ (vs. SCE), scan rate of $5 \mathrm{mV} \cdot \mathrm{s}^{-1}$, and temperature of $45^{\circ} \mathrm{C}$ with different number of scans $(3,4,5$, and 6).

XRD pattern confirmed that the phase component of obtained coatings is not affected by number of scans (Figure 11).

The variations of mass, thickness, and adhesion between HAp-MWCNTs 0.5 coatings and substrate are depicted in Table 4. With increasing number of scans, the mass and thickness increased but the adhesion decreased.

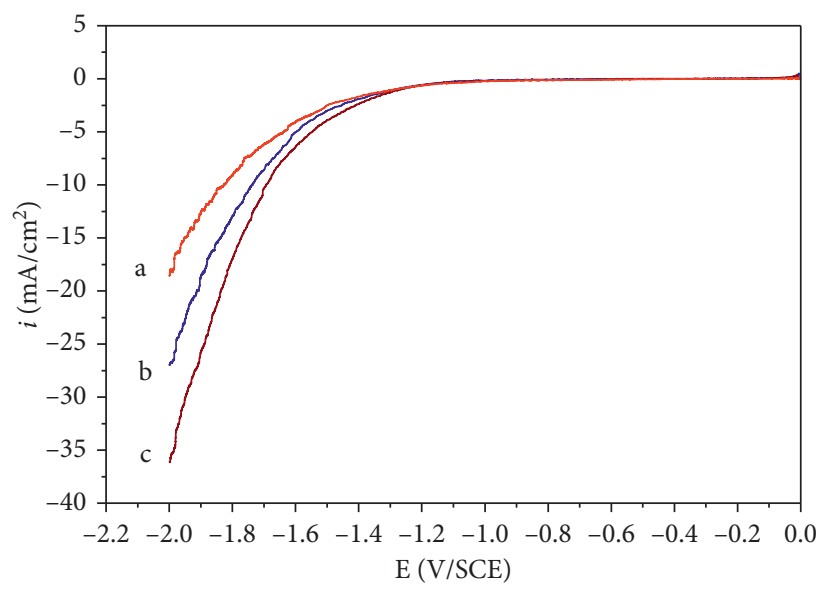

Figure 8: The cathodic polarization curves of the Ti6Al4V electrode in the electrolyte solution at different temperature: (a) $30^{\circ} \mathrm{C}$, (b) $45^{\circ} \mathrm{C}$, and (c) $60^{\circ} \mathrm{C}$.

TABle 3: Mass, thickness, and adhesion between HAp-MWCNT coatings and Ti6Al4V following synthesis temperature.

\begin{tabular}{lccc}
\hline $\begin{array}{l}\text { Temperature } \\
\left({ }^{\circ} \mathrm{C}\right)\end{array}$ & $\begin{array}{c}\text { Mass }(\mathrm{mg} / \\
\left.\mathrm{cm}^{2}\right)\end{array}$ & $\begin{array}{c}\text { Thickness } \\
(\mu \mathrm{m})\end{array}$ & $\begin{array}{c}\text { Adhesion } \\
(\mathrm{MPa})\end{array}$ \\
\hline 30 & $1.18 \pm 0.05$ & $3.4 \pm 0.65$ & $12.0 \pm 0.42$ \\
45 & $\mathbf{2 . 0 8} \pm 0.06$ & $\mathbf{6 . 3} \pm 0.72$ & $\mathbf{1 0 . 4} \pm 0.36$ \\
60 & $3.81 \pm 0.03$ & $11.4 \pm 1.13$ & $6.0 \pm 0.52$ \\
\hline
\end{tabular}

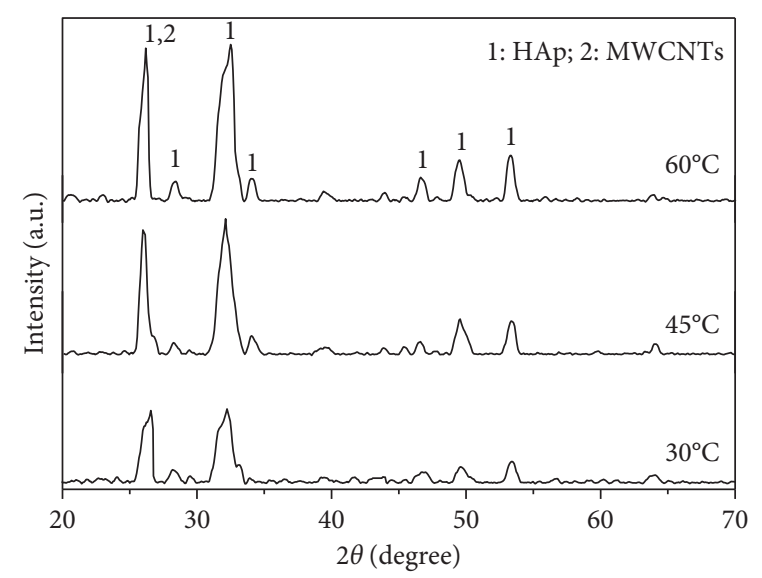

FIgURE 9: XRD pattern of HAp-MWCNTs synthesized at $30^{\circ} \mathrm{C}$, $45^{\circ} \mathrm{C}$, and $60^{\circ} \mathrm{C}$.

After 3 scans, a nonhomogeneous HAp-MWCNT 0.5 with low density $\left(0.92 \mathrm{mg} / \mathrm{cm}^{2}\right)$ is formed on the substrate. Consequently, the adhesion strength can be determined in this case. After 4 and 5 scans, the quality of HAp$\mathrm{MWCNT}_{0.5}$ films was much improved with lower roughness, higher density, and a complete coverage over the surface of the Ti6Al4V substrate. A better adhesion strength of $10 \mathrm{MPa}$ was also obtained at the number of scans of 5. But up to 6 scans, the adhesion was strongly decreased to $7 \mathrm{MPa}$ since the film now is too thick and 


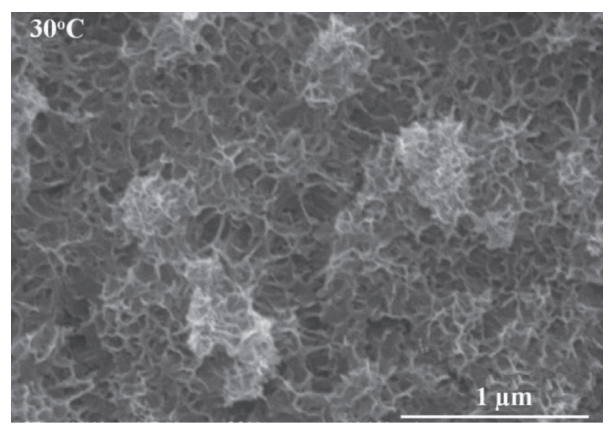

(a)

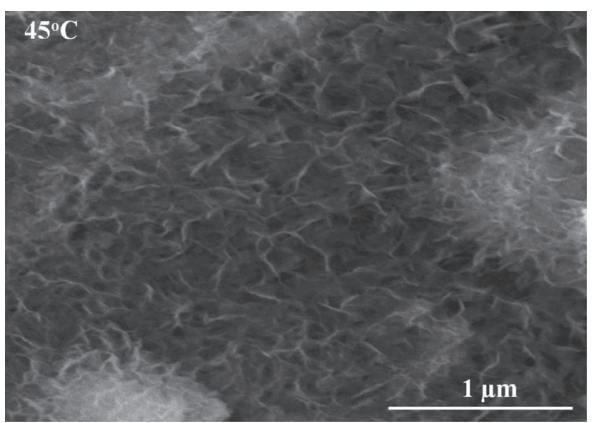

(b)

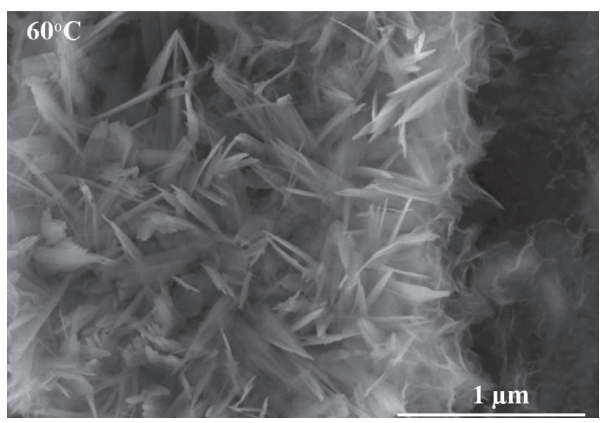

(c)

FIgURE 10: SEM images of HAp-MWCNTs ${ }_{0.5} / \mathrm{Ti} \mathrm{AAl} 4 \mathrm{~V}$ synthesized at different temperature.

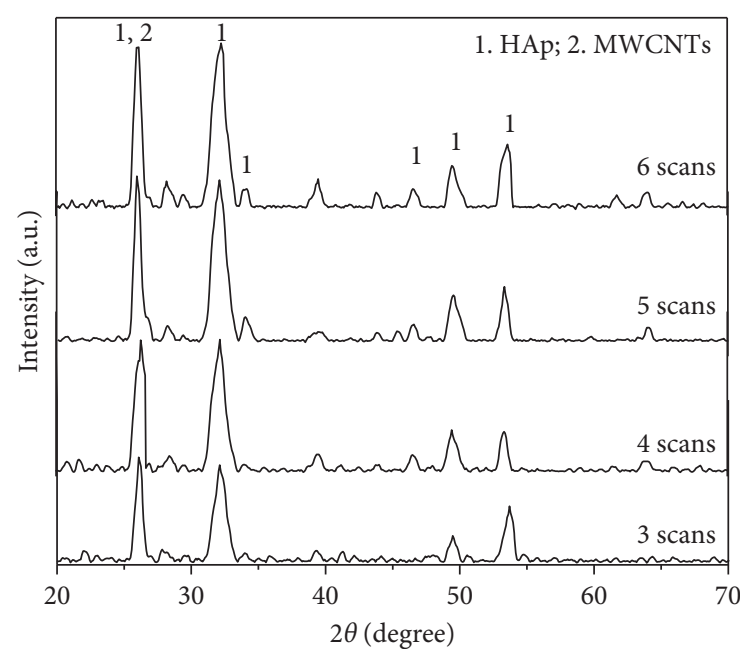

FIGURE 11: XRD pattern of HAp-MWCNTs synthesized with different scanning time.

TABLE 4: The variation of mass, thickness, and adhesion between HAp-MWCNTs and Ti6Al4V with different scanning time (number of scans).

\begin{tabular}{lccc}
\hline Scans & $\begin{array}{c}\text { Mass }(\mathrm{mg} / \\
\left.\mathrm{cm}^{2}\right)\end{array}$ & $\begin{array}{c}\text { Thickness }(\mu \mathrm{m}) \\
4288-1998\end{array}$ & $\begin{array}{c}\text { Adhesion strength } \\
(\mathrm{MPa})\end{array}$ \\
\hline 3 & $0.92 \pm 0.12$ & $3.0 \pm 0.54$ & - \\
4 & $1.92 \pm 0.06$ & $6.1 \pm 0.61$ & $10.7 \pm 0.82$ \\
5 & $\mathbf{2 . 0 8} \pm 0.05$ & $\mathbf{6 . 3} \pm 0.64$ & $\mathbf{1 0 . 4} \pm 0.61$ \\
6 & $2.32 \pm 0.02$ & $7.5 \pm 0.73$ & $7.0 \pm 0.95$ \\
\hline
\end{tabular}

porous. In summary, the optimal number of scans was chosen to be 5 .

Based on the above results on the effect of the scanning potential range, MWCNTs amount, synthesis temperature, and number of scans, we offer the optimal condition to synthesize the HAp-MWCNT coating on Ti6Al4V by electrodeposition as following: scanning potential range from 0 to $-2.0 \mathrm{~V} / \mathrm{SCE}, 5$ scans, and scanning rate of $5 \mathrm{mV} / \mathrm{s}$ at $45^{\circ} \mathrm{C}$ in the electrolyte solution containing $0.5 \mathrm{~g} / \mathrm{L}$ of MWCNTs. HAp-MWCNTs synthesized at this condition have a crystal structure which are composed of phases of HAp and MWCNTs with the thickness of $6.3 \mu \mathrm{m}$ and the adhesion of $10 \mathrm{MPa}$. The optimal conditions obtained in this study are not completely similar to the optimal conditions for HApMWCNTs on 316L SS in our previous publication [17-19]. It is clear that the study on synthesis of HApMWCNT coating on the different substrates is necessary because in implant areas with large tonnage that require a large tonnage such as the leg, femur, and hip, the use of Ti6Al4V materials are necessary.

3.2. Coating Mechanical Properties. The elastic modulus (determined from tensile stress curves) was about 115, 121, and $126 \mathrm{GPa}$ for the bare electrode, HAp, and HAp$\mathrm{MWCNTs}_{0.5}$ coating, respectively (Figure 12). Meanwhile, the hardness of HAp-MWCNTs $\mathrm{MW}_{0.5}$ coating $(6 \mathrm{GPa})$ is significantly higher than that of HAp coating $(5.1 \mathrm{GPa})$. The improved elasticity and hardness of the HAp-MWCNTs $\mathrm{MW}_{0.5}$ 


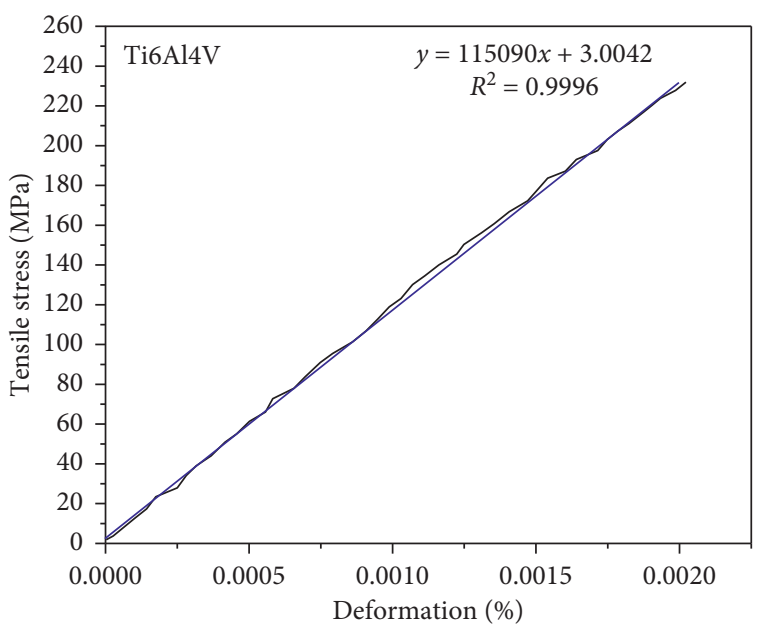

(a)

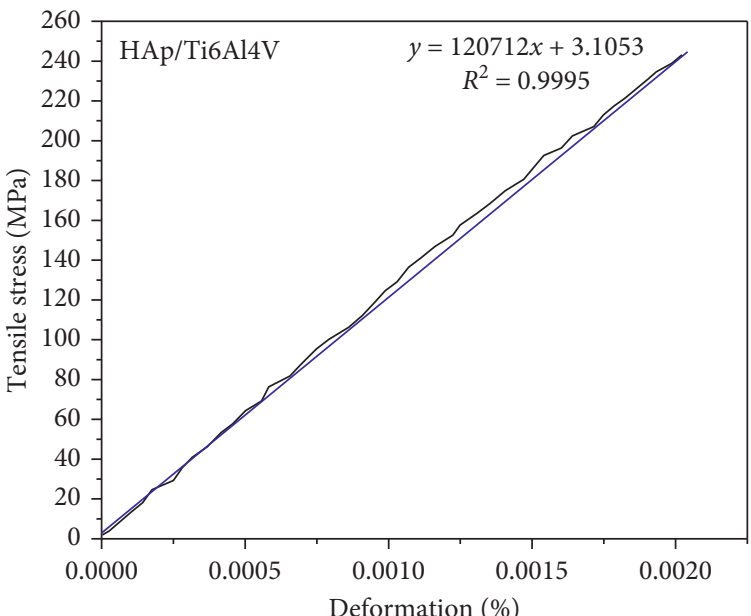

(b)

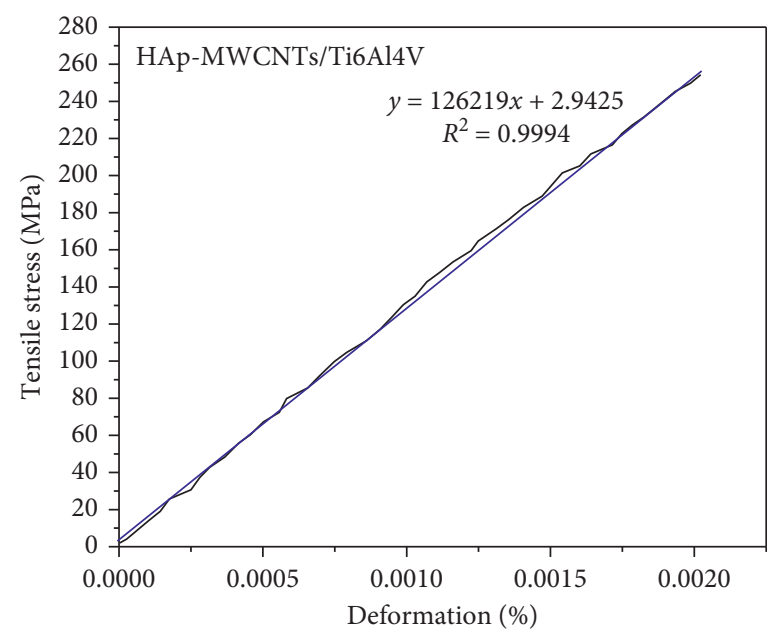

(c)

Figure 12: Relationship between the tensile stress and the deformation of (a) Ti6Al4V, (b) HAp/Ti6Al4V, and (c) HAp-MWCNTs . $_{0.5} /$ Ti6Al4V.

TABle 5: $\mathrm{Ca}^{2+}$ concentrations released from the HAp or HApMWCNTs coatings.

\begin{tabular}{lcc}
\hline $\begin{array}{l}\text { Immersion time } \\
\text { (day) }\end{array}$ & \multicolumn{2}{c}{$\mathrm{Ca}^{2+}(\mathrm{mg} / \mathrm{L})$} \\
\hline 7 & $21.3 \pm 0.03$ & $12.6 \pm 0.02$ \\
14 & $24.9 \pm 0.04$ & $16.3 \pm 0.02$ \\
21 & $29.5 \pm 0.02$ & $17.8 \pm 0.03$ \\
\hline
\end{tabular}

coating must be benefited from high mechanical flexibility and strength of carbonaceous material present in the coating.

3.3. Dissolution of the Coatings. The dissolution of HAp and HAp-MWCNTs ${ }_{0.5}$ coatings was determined by $\mathrm{Ca}^{2+}$ released concentration when these materials were immersed in $0.9 \%$ of $\mathrm{NaCl}$ solution. The data in Table 5 shows that the dissolution of HAp coating was higher than that of HAp-
MWCNTs coating at all immersion times. It means that MWCNTs plays the role in reducing the solubility of the coating because of the formation of hydrogen bonding between MWCNTs and HAp.

\section{Conclusions}

The HAp-MWCNT coatings were successfully electrodeposited on the surface of Ti6Al4V electrodes. The optimal synthesis conditions were obtained at the stopped potential of $-2.0 \mathrm{~V} / \mathrm{SCE}, 5$ scans, and $5 \mathrm{~m} \cdot \mathrm{s}^{-1}$ at $45^{\circ} \mathrm{C}$ with the presence of MWCNTs $\left(0.5 \mathrm{~g} \cdot \mathrm{L}^{-1}\right)$ in the electrolyte solution. FTIR spectra and XRD patterns have firmly confirmed the presence of HAp and MWCNTs and the absence of add products on the modified electrodes. More importantly, it was found that the presence of MWCNTs has reinforced mechanical behaviors as well as improved the stability of HAp-based coatings. These findings support further applications of HAp-MWCNT nanocomposites in orthopedics in future. 


\section{Data Availability}

All of the data used to support the findings of this study are included within the article.

\section{Conflicts of Interest}

The authors declare that there are no conflicts of interest regarding the publication of this paper.

\section{Acknowledgments}

This research was funded by the Institute for Tropical Technology (ITT) and Graduate University of Science and Technology (GUST), Vietnam Academy of Science and Technology.

\section{References}

[1] P. M. Ajayan, "Nanotubes from carbon," Chemical Reviews, vol. 99, no. 7, pp. 1787-1800, 1999.

[2] J. Chlopek, B. Czajkowska, B. Szaraniec, E. Frackowiak, K. Szostak, and F. Beguin, "In vitro studies of carbon nanotubes bio-compatibility," Carbon, vol. 44, no. 6, pp. 1106-1111, 2006.

[3] R. L. Price, M. C. Waid, K. M. Haberstroh, and T. J. Webster, "Selective bone cell adhesion on formulations containing carbon nanofibers," Biomaterials, vol. 24, pp. 1877-1887, 2003.

[4] A. Peigney, "A tougher ceramics with nanotubes," Nature Materials, vol. 2, no. 1, pp. 15-16, 2003.

[5] D. Lahiri, S. Ghosh, and A. Agarwal, "Carbon nanotube reinforced hydroxyapatite composite for orthopedic application: a review," Materials Science and Engineering: C, vol. 32, no. 7, pp. 1727-1758, 2012.

[6] K. Balani, R. Anderson, T. Laha et al., "Plasma-sprayed carbon nanotube reinforced hydroxyapatite coatings and their interaction with human osteoblasts in vitro," Biomaterials, vol. 28, no. 4, 2007.

[7] B. Kundu, M. K. Sinha, M. K. Mitra, and D. Basu, "Fabrication and characterization of porous hydroxyapatite ocular implant followed by anin vivo study in dogs," Bulletin of Materials Science, vol. 27, no. 2, pp. 133-140, 2004.

[8] S. Liu, H. Li, Y. Su, Q. Guo, and L. Zhang, "Preparation and properties of in-situ growth of carbon nanotubes reinforced hydroxyapatite coating for carbon/carbon composites," $\mathrm{Ma}$ terials Science and Engineering: C, vol. 70, pp. 805-811, 2017.

[9] S. Constanda, M. S. Stan, C. S. Ciobanu et al., "Carbon nanotubes-hydroxyapatite nanocomposites for an improved osteoblast cell response," Journal of Nanomaterials, vol. 2016, Article ID 3941501, 10 pages, 2016.

[10] M. Susmita, S. Swarnendu, and C. Abhijit, "Mechanical and in-vitro performance of CNT reinforced hydroxyapatite prepared by a shear mixing method," Journal Nanomedicine \& Nanotechnology, vol. 4, no. 3, 2014.

[11] M. Susmita, K. Biswanath, S. Swarnendu, and C. Abhijit, "Improved properties of hydroxyapatite-carbon nanotube biocomposite: mechanical, in vitro bioactivity and biological studies," Ceramics International, vol. 40, no. 4, pp. 5635-5643, 2014.

[12] E. Długon, W. Niemiec, A. Frazek-Szczypta, P. Jelen, M. Sitarz, and M. Błazewicz, "Spectroscopic studies of electrophoretically deposited hybrid HAp/CNT coatings on titanium," Spectrochimica Acta Part A: Molecular and Biomolecular Spectroscopy, vol. 133, pp. 872-875, 2014.

[13] D. Gopi, E. Shinyjoy, M. Sekar, M. Surendiran, L. Kavitha, and T. S. Sampath Kumar, "Development of carbon nanotubes reinforced hydroxyapatite composite coatings on titanium by electrodeposition method," Corrosion Science, vol. 73, pp. 321-330, 2013.

[14] P. Xibo, Z. Yongxiang, H. Rui et al., "Single-walled carbon nanotubes/hydroxyapatite coatings on titanium obtained by electrochemical deposition," Applied Surface Science, vol. 295, pp. 71-80, 2014.

[15] N. Eliaz and M. Eliyahu, "Electrochemical processes of nucleation and growth of hydroxyapatite on titanium supported by real-time electrochemical atomic force microscopy," Journal of Biomedical Materials Research Part A, vol. 80A, no. 3, 2006.

[16] C. Oldani and A. Dominguez, "Titanium as a biomaterial for implants," in Recent Advances in Arthroplasty, Dr. Samo Fokter, Ed., IntechOpen, London, UK, 2012.

[17] N. T. Thom, P. T. Nam, N. T. Phuong et al., "Electrodeposition of hydroxyapatite/functionalized carbon nanotubes (HAp/fCNTs) coatings on the surface of 316L stainless steel," Vietnam Journal of Science and Technology, vol. 55, no. 6, pp. 706-715, 2017.

[18] N. T. Thom, P. T. Nam, D. T. M. Thanh et al., "Investigation of the condition to synthesize HAp/CNTs coatings on 316LSS," Vietnam Journal of Science and Technology, vol. 56, no. 4, pp. 50-42, 2018.

[19] N. T. Thom, P. T. Nam, C. T. Hong, and N. T. Phuong, "Electrochemical behavior of HAp/CNTs/316LSS coatings into simulated body fluid solution," Vietnam Journal of Chemistry, vol. 56, no. 4, pp. 452-459, 2018.

[20] N. V. Chuc, N. D. Dung, P. N. Hong et al., "Synthesis of carbon nanotubes on steel foils," Journal of the Korean Physical Society, vol. 52, no. 5, pp. 1368-1371, 2008.

[21] ASTM International, Standard Test Method for Shear Testing of Calcium Phosphate Coatings and Metallic Coatings: ASTM F1044, ASTM International, West Conshohocken, PA, USA, 2005, http://www.astm.org.

[22] R. Narayanan, T.-Y. Kwon, and K.-H. Kim, "Direct nanocrystalline hydroxyapatite formation on titanium from ultrasonated electrochemical bath at physiological $\mathrm{pH}$," Materials Science and Engineering: C, vol. 28, no. 8, pp. 1265-1270, 2008.

[23] Y. H. Huei, B. M. Yankuba, H. Wan-Ning et al., "Effect of hydroxyapatite formation on titanium surface with bone morphogenetic protein-2 loading through electrochemical deposition on MG-63 cells," Materials, vol. 11, no. 10, p. 1897, 2018.

[24] M. S. Djosic, V. Panic, J. Stojanovic, M. Mitric, and V. B. Miskovic-Stankovic, "The effect of applied current density on the surface morphology of deposited calcium phosphate coatings on titanium," Colloids and Surfaces A: Physicochemical Engineering Aspects, vol. 400, pp. 36-43, 2012.

[25] P. Quentin, O. Florian, D. Sandrine, C. Jérôme, W. Fabienne, and B. Sylvie, "Development and characterization of biomimetic carbonated calcium-deficient hydroxyapatite deposited on carbon fiber scaffold," Journal of Carbon Research, vol. 4, p. 25, 2018.

[26] L. Morejón-Alonso, C. Mochales, L. Nascimento, and W.-D. Müller, "Electrochemical deposition of $\mathrm{Sr}$ and $\mathrm{Sr} / \mathrm{Mg}$ co-substituted hydroxyapatite on Ti-40Nb alloy," Materials Letters, vol. 248, pp. 65-68, 2019. 
[27] T.-T. Li, L. Ling, M.-C. Lin et al., "Effect of hydrogen peroxide concentration on the nanostructure of hydroxyapatite coatings via ultrasonicassisted electrodeposition"” Materials Letters, vol. 261, 2020.

[28] B. P. Vinayan, R. Nagar, V. Raman, N. Rajalakshmi, K. S. Dhathathreyan, and S. Ramaprabhu, "Synthesis of graphene-multiwalled carbon nanotubes hybrid nanostructure by strengthened electrostatic interaction and its lithium ion battery application," Journal Materials Chemical, vol. 248, no. 22, pp. 9949-9956, 2012.

[29] W. Jing, L. Zhan, L. Shicheng et al., "Highly mesoporous activated carbon electrode for capacitive deionization," Separation and Purification Technology, Elsevier, Amsterdam, Netherlands, 2013.

[30] A. O. Lobo, F. R. Marciano, I. Regiani, J. T. Matsushima, S. C. Ramos, and E. J. Corat, "Influence of temperature and time for direct hydroxyapatite electrodeposition on superhydrophilic vertically aligned carbon nanotube films," Journal of Nanomedicine \& Nanotechnology, vol. 6, no. 2, 2011. 